\title{
Cutaneous thermal thresholds in patients with painful burning feet
}

\author{
Shelagh J M Smith, Z Ali, Clare J Fowler
}

\begin{abstract}
Small nerve fibre sensory function was assessed by psychophysical estimates of cutaneous thermal thresholds in $\mathbf{3 0}$ patients who presented with the symptoms of painful burning feet. Thresholds were abnormal in 12 and normal in 18 patients although symptoms in the two groups were very similar. Various hypotheses for the mechanism of pain in small fibre neuropathy have been proposed previously and these are discussed, but the cause of symptoms in patients with normal thresholds, is unknown. The possibility exists that these patients have a neuropathic disorder which affects only those unmyelinated fibres involved with pain.
\end{abstract}

The symptoms and signs of a peripheral neuropathy depend on whether the neuropathic process produces "positive" or "negative" features. ${ }^{1}$ Negative manifestations result in loss of light touch, vibration and joint position sense if predominantly large fibres are affected. If small fibre loss predominates, pain and temperature sensation are defective, and the patient may present with painless plantar ulceration. Neuropathic damage which causes small myelinated and unmyelinated fibres (those fibres which convey nociception and thermal sensations) to become generators of positive phenomena, may present with pain in a glove and stocking distribution or just pain and burning in the feet.

In patients complaining of painful feet, a diagnosis of small fibre neuropathy should be considered. Appropriate investigation of this disorder has presented a considerable problem in the past. Nerve conduction studies with surface electrodes measure conduction in the fastest conducting, large diameter myelinated fibres and are therefore of little value in detecting small fibre neuropathy. Near nerve needle electrode recordings of compound nerve action potentials, with averaging over a 1000 times, yields waveforms in which late, slowly conducted potentials can be resolved, ${ }^{2}$ but do not show activity of unmyelinated fibres. Of the few methods available which can assess unmyelinated fibre function, microneurography ${ }^{3}$ and morphometry ${ }^{4}$ are well established, but both are invasive and unsuitable to apply routinely. However, psychophysical estimates of cutaneous thermal thresholds are simple, non-invasive tests, acknowledged to be of value in the assessment of small fibre sensory function. ${ }^{5-7}$
Data from human microneurography experiments have shown that the sensation of cooling is conveyed in small myelinated fibres ${ }^{8}$ and that of warming in unmyelinated fibres. ${ }^{39}$ The conduction velocity of each of the thermal sensations generated when using the apparatus employed here was estimated in earlier reaction time experiments ${ }^{10}$ as being $0.5-0.2 \mathrm{~m} / \mathrm{s}$ for warming and $2 \cdot 1-0.8 \mathrm{~m} / \mathrm{s}$ for cooling: velocities consistent with conduction in unmyelinated and small myelinated fibres respectively.

We have looked for evidence of small fibre dysfunction using psychophysical estimation of cutaneous thermal thresholds in a group of patients presenting with pain and burning in their feet.

\section{Patients and methods}

Patients

Thirty patients (six male, 24 female, age range 21-81 years) with painful, burning feet as their predominant symptom, were investigated. They had all been referred by neurologists from the National Hospital for Neurology and Neurosurgery, suspected on clinical grounds of suffering from small fibre neuropathy, other possible causes such as orthopaedic disorders and inflammatory fasciitis having been excluded as far as possible on clinical grounds. A clinical history was obtained by one of the investigators (SJMS or CJF), corroborated when necessary from the case notes made by the referring clinician.

Group differences in symptoms and signs were compared using the chi-squared test.

\section{Nerve conduction studies}

All patients underwent standard nerve conduction studies using surface recording and stimulating electrodes. ${ }^{112}$ Sensory action potentials of the median, ulnar, and sural nerves were measured and motor conduction velocity in the ulnar and lateral popliteal or posterior tibial nerves. Measurements were made at room temperature without heating the limb.

Psychophysical estimation of thermal thresholds Cutaneous thermal thresholds were estimated using a computer controlled warm and cold stimulus generator. ${ }^{13}$ Stimuli were delivered from a thermode made of a Peltier junction module, sandwiched between a thin copper plate and air-cooling fins, with a thermo-couple embedded in the copper plate to monitor the temperature at the skin-thermode junc- 
tion. The test consisted of a warning tone followed by a dynamic thermal ramp stimulus of predetermined intensity and the subject asked to respond "yes" or "no" as to whether the stimulus was felt. Stimuli were of progressively diminishing amplitude and randomly interspersed among real stimuli were "catch" trials, when no temperature change followed the warning tone; these allow the reliability of the subject to be assessed. Threshold was calculated by the microcomputer using an algorithm similar to that devised by Dyck ${ }^{14}$ in which the mean was taken of all values between the last three turns, or in this instance "no's". On average eight test levels are needed to define threshold using this method.

Threshold for cooling was tested first as all subjects found the cooling stimulus less subtle than the warming one. The test protocol for warming was identical except that the polarity of the current through the thermode was reversed.

The thermode was attached to the nonkeratinised skin on the instep of the foot. Both sensory modalities were tested on one foot and if those results were abnormal the other foot was also tested to confirm the deficit was genuine. As with all psychophysical tasks the subject's full cooperation was critical and efforts were made to ensure an abnormal result was due to impaired sensation rather than an inability to perform the test adequately.

Control data were collected earlier from 116 subjects, 60 men and 56 women, age range 1873. These were mainly healthy volunteers recruited from hospital personnel, although healthy subjects over 65 years old were sought outside the hospital. The effect of age on thresholds was examined using least squares regression methods and examination of the residuals showed that the simple linear regression formula provided the best fit to the data. ${ }^{13}$ Ninety five per cent confidence limits based on two standard deviations were calculated for each thermal modality, and in men and women separately. Results from the patients were superimposed on graphs of the control data.

\section{Nerve biopsy}

Four patients had sural nerve biopsy under local anaesthetic.
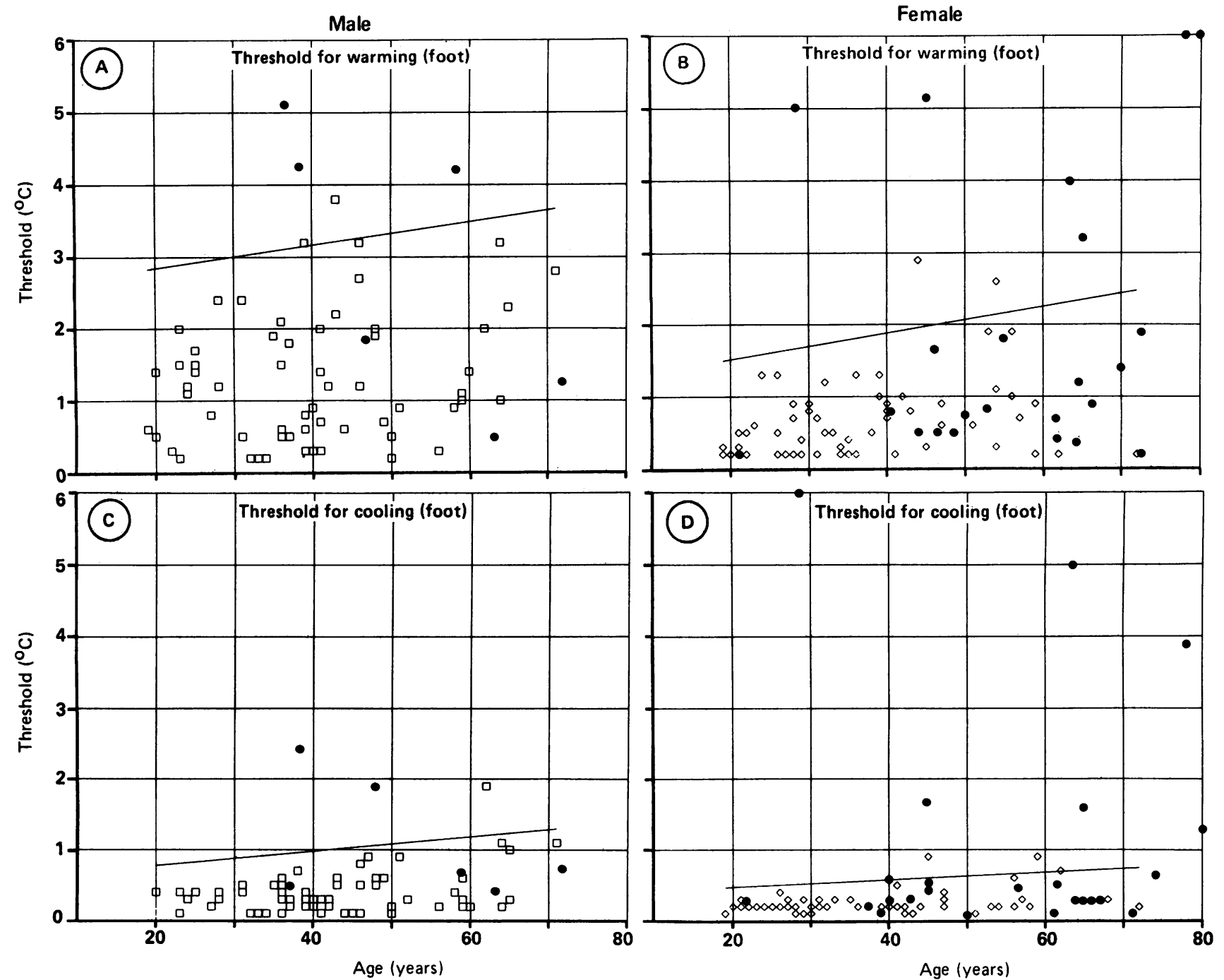

Figure Thresholds for warming (a) and cooling (c) in males and warming (b) and cooling (d) in females, measured on the sole of the foot. The graphs show thresholds for control subjects (open symbols) and patients (solid circles). The line indicates upper limit of normal threshold for age (mean $+2 S D) .13$ 
Table 1 Clinical findings

\begin{tabular}{|c|c|c|c|}
\hline & $\begin{array}{l}\text { Normal TT } \\
n=18\end{array}$ & $\begin{array}{l}\text { Abnormal } T T \\
n=12\end{array}$ & \\
\hline $\begin{array}{l}\text { M:F } \\
\text { Mean age (range) }\end{array}$ & $\begin{array}{l}2: 16 \\
54 \cdot 4(21-72)\end{array}$ & $\begin{array}{l}4: 8 \\
55 \cdot 6(28-81)\end{array}$ & NS ${ }^{\star}$ \\
\hline $\begin{array}{l}\text { Symptoms } \\
\text { Pain alone } \\
\text { Burning alone } \\
\text { Pain and burning } \\
\text { Relief by cooling } \\
\text { Relief by movement } \\
\text { Mean duration (range) }\end{array}$ & $\begin{array}{l}6(33 \%) \\
8(44 \%) \\
3(22 \%) \\
2(11 \%) \\
8(44 \%) \\
5 \cdot 7(9 \mathrm{~m}-20 \mathrm{y})\end{array}$ & $\begin{array}{l}3(25 \%) \\
3(25 \%) \\
7(58 \%) \\
3(25 \%) \\
3(25 \%) \\
3 \cdot 7(2 w-20 y)\end{array}$ & $\begin{array}{l}\text { NS } \\
\text { NS } \\
\text { p }<0.02 \\
\text { NS } \\
\text { NS } \\
\text { NS }\end{array}$ \\
\hline $\begin{array}{l}\text { Signs } \\
\text { Reduced pinprick }\end{array}$ & $2(11 \%)$ & $7(58 \%)$ & $\mathrm{p}<0.01$ \\
\hline
\end{tabular}

\section{Results}

Warming and cooling thresholds were within the normal range in 18 patients, age range 2172 years, mean age $54 \cdot 1$. One or both thresholds were abnormal in 12 patients, age range 28-81 years, mean age $55 \cdot 6$. Six of the 12 patients had abnormal thresholds for both warming and cooling; four had only abnormal warming thresholds and two, only an abnormal cooling threshold (figure).

The mean duration of symptoms in patients with abnormal thresholds (mean 3.7 years, range 2 weeks -20 years, SD 5.3) was less than that in patients with normal thresholds (mean 5.6 years, range 9 months -20 years, SD 5.6) although this difference was not statistically significant.

Six patients with normal thresholds and three patients with abnormal thresholds complained of painful feet as their only symptom (table 1). The nature of the pain varied; some patients described a sharp shooting pain, whereas others complained of a dull continuous ache or throbbing pressure felt in the feet and lower part of the legs. In some cases, the pain had an unpleasant dysaesthetic quality, and was likened to a sensation of insects crawling beneath the skin of the feet or pins being stuck into the legs. Most patients found that the pain was worse at night. Two patients with normal thresholds and three patients with abnormal thresholds could obtain some relief from their pain either by hanging their legs out of bed, walking around, or applying pressure to the soles of their feet.

There was no obvious difference between the two groups for quality or severity of pain.

Eight patients with normal thresholds and three with abnormal thresholds described a

Table 2 Nerve conduction studies

\begin{tabular}{|c|c|c|c|c|}
\hline & Group & Mean (range) & $S D$ & $p$ \\
\hline \multirow{2}{*}{$\begin{array}{l}\text { Sural } \\
\text { SAP } \\
\text { amplitude (uV) }\end{array}$} & Normal TT & $18 \cdot 9(6-60)$ & $14 \cdot 3$ & \multirow{2}{*}{$p<0.01$} \\
\hline & Abnormal TT & $9 \cdot 6(0-20)$ & 5.9 & \\
\hline \multirow{2}{*}{$\begin{array}{l}\text { Median } \\
\text { SAP } \\
\text { amplitude (uV) }\end{array}$} & Normal TT & $20 \cdot 2(10-34)$ & 8.03 & \multirow{2}{*}{ NS } \\
\hline & Abnormal TT & $15 \cdot 0(5-21)$ & 5.9 & \\
\hline \multirow{2}{*}{$\begin{array}{l}\text { Upper } \\
\operatorname{limb~MCV} \\
(\mathrm{m} / \mathrm{s})\end{array}$} & Normal TT & $60(49-71)$ & $7 \cdot 34$ & \multirow{2}{*}{ NS } \\
\hline & Abnormal TT & $61(50-73)$ & $7 \cdot 72$ & \\
\hline \multirow{2}{*}{$\begin{array}{l}\text { Lower } \\
\operatorname{limb} M C V \\
(\mathrm{~m} / \mathrm{s})\end{array}$} & Normal TT & $48(40-64)$ & $5 \cdot 74$ & \multirow{2}{*}{ NS } \\
\hline & Abnormal TT & $50(40-65)$ & $9 \cdot 88$ & \\
\hline
\end{tabular}

burning sensation in their feet as their only symptom. Five patients (three with abnormal and two with normal thresholds) found relief from the burning feeling by cooling their feet or legs in a bucket of cold water. One patient (with normal thresholds) found the burning sensations to be worse in cold weather.

There was a significant difference $(p<0.02$, chi-squared test) in the number of patients from each group who complained of both burning and pain in their feet; seven patients with abnormal thresholds, but only three patients with normal thresholds described both symptoms. Patients with abnormal thresholds were also more likely to have abnormalities on clinical examination with a reduction in pinprick sensation in the lower limbs in seven compared with only two of patients with normal thresholds. This difference was significant ( $\mathrm{p}<0.01$, chi-squared test).

Nerve conduction tests were abnormal in only one case; this patient also had abnormal thresholds for warming and cooling. Sensory action potentials (sural $4 \mathrm{uv}$, median $5 \mathrm{uv}$ ) and the compound muscle action potential from the extensor digitorum brevis $(2.8 \mathrm{mV})$ were of low amplitude; motor conduction velocity in the ulnar and lateral popliteal nerves was normal.

None of the remaining patients had abnormal sensory action potentials or motor conduction velocities, although the mean amplitude of the sural sensory action potential was smaller (see table 2) in the group with abnormal thresholds ( $p<0.01$, Mann-Whitney U test).

Four patients in the group with abnormal thresholds had sural nerve biopsies with morphometry, confirming a predominantly small fibre neuropathy.

A possible aetiological factor was identified in eight of the 12 patients with abnormal thermal thresholds (table 3). Two gave a history of alcohol abuse; three patients were known or found to be diabetic (one insulin dependent and two maturity onset). In one case, the sural nerve biopsy showed evidence of vasculitis (case 7); this patient's symptoms appeared a few days after he had been given Cotrimoxazole for sinusitis. He complained of very severe pain and burning and had abnormal nerve conduction studies in addition to abnormal thresholds. In one further patient, (case 10) polycythaemia was thought to be responsible for the neuropathy and in the remaining case, the diagnosis was a drug related (perhexilene) neuropathy (case $1 \mathrm{i}$ ).

Of the 18 patients with normal thresholds, none was found to be diabetic or to have any other history relevant for a small fibre neuropathy. Three patients had long standing intermittent low back pain, two had a history of ischaemic heart disease, one was found to have an iron deficiency anaemia and one was a chronic epileptic on long term anticonvulsant medication (phenytoin).

\section{Discussion}

Psychophysical estimates of thermal thresholds in this group of 30 patients with painful, burning sensations in their feet demonstrated abnormalities compatible with a small fibre neuropathy in only $40 \%$. 
Table 3 Details of patients with abnormal thresholds

\begin{tabular}{|c|c|c|c|c|c|c|}
\hline Patient & Age & Symptoms & Duration & Relevant history & Biopsy & $N C S$ \\
\hline $\begin{array}{r}1 \\
2 \\
3 \\
4 \\
5 \\
6 \\
7 \\
8 \\
9 \\
10 \\
11 \\
12\end{array}$ & $\begin{array}{l}28 \\
78 \\
46 \\
55 \\
59 \\
36 \\
39 \\
45 \\
63 \\
66 \\
73 \\
81\end{array}$ & $\begin{array}{l}\text { Burning } \\
\text { Burning } \\
\text { Pain } \\
\text { Pain } \\
\text { Pain } \\
\text { Pain + burning } \\
\text { Pain + burning } \\
\text { Pain + burning } \\
\text { Pain + burning } \\
\text { Pain + burning } \\
\text { Pain + burning } \\
\text { Pain + burning }\end{array}$ & $\begin{array}{l}6 \mathrm{mths} \\
2 \mathrm{yrs} \\
5-6 \mathrm{yrs} \\
3-4 \mathrm{yrs} \\
20 \mathrm{yrs} \\
4 \mathrm{yrs} \\
2 \mathrm{wks} \\
2 \mathrm{yrs} \\
2 \mathrm{yrs} \\
2 \mathrm{yrs} \\
1 \mathrm{yr} \\
18 \mathrm{mths}\end{array}$ & $\begin{array}{l}\text { Diabetes } \\
\overline{\text { Diabetes }} \\
\text { Alcohol abuse }++ \\
\text { Alcohol abuse }++ \\
\overline{\text { Vasculitis }} \\
\overline{\text { Diabetes }} \\
\text { Polycythemia } \\
\text { Drug related } \\
-\end{array}$ & $\begin{array}{l}- \\
- \\
- \\
\overline{-} \\
\text { SFN } \\
\overline{\text { SFN }} \\
\text { SFN } \\
\text { SFN }\end{array}$ & $\begin{array}{l}\text { Normal } \\
\text { Normal } \\
\text { Normal } \\
\text { Normal } \\
\text { Normal } \\
\text { Normal } \\
\text { Abnormal } \\
\text { Normal } \\
\text { Normal } \\
\text { Normal } \\
\text { Normal } \\
\text { Normal }\end{array}$ \\
\hline
\end{tabular}

NCS—nerve conduction studies.

SFN-small fibre neuropathy.

Of the 12 patients with abnormal thermal thresholds, four had nerve biopsy which confirmed damage to a significant proportion of small fibres; in all four patients a possible aetiological factor was present, that is, diabetes, vasculitis, neuropathy related to polycythaemia and drug related neuropathy. Of the eight patients with abnormal thresholds who did not have a biopsy, a possible relevant history was found in four (diabetes or alcohol excess) and a combination of this and the abnormal thresholds was considered sufficient by the referring clinician to make a diagnosis of small fibre neuropathy. In the four remaining patients, no definite diagnosis was reached. None of the patients with normal thresholds had medical histories suggesting a cause of small fibre neuropathy and none had sural nerve biopsies.

The mean amplitude of the sural sensory action potential was smaller in the 12 patients with abnormal thermal thresholds, although in only one patient was the amplitude below the lower limit of normal for our laboratory. This suggests additional large fibre involvement in some patients.

Although there was no clear difference in the nature of the symptoms between the two groups, patients with both pain and burning in their feet or those who had reduced sensation of pinprick on the feet, were more likely to have abnormal thermal thresholds.

It is unlikely that the thermal threshold testing system employed in this study was insufficiently sensitive to detect abnormalities of sensation. The control ranges for thresholds on the soles of the feet using this device showed a positive correlation with age, ${ }^{13}$ which is a powerful indicator of biological sensitivity. Also in another study 11 patients who had had diabetes for more than 20 years but were without symptoms of neuropathy, were subjected to a battery of sensory tests and nerve conduction studies, and an impairment of perception of warming using the technique employed here, was the commonest abnormality. ${ }^{15}$ Perception of warming requires a high degree of spatial summation ${ }^{16}$ and since the proportion of unmyelinated fibres which convey this modality is low, any peripheral nerve pathology which damages the population of unmyelinated afferents will be manifest by causing an abnormally high threshold for warming. Thus in $60 \%$ of this group of patients with symptoms of pain and burning in the feet, a test which is sensitive and appropriate for unmyelinated afferent dysfunction, was normal. It can, however, be argued that an abnormality might have been demonstrated had estimates of thermal pain been made (although not technically feasible using the apparatus employed here) since it is now recognised that painful syndromes exist in which heat and cold hyperalgesia can be demonstrated in the absence of warm or cold sensory deficits. ${ }^{17}$

In a review of aspects of pain in peripheral neuropathy, Thomas made the point that spontaneous pain is not a feature of neuropathies which cause a selective loss of large myelinated fibres but is a prominent symptom of neuropathies that have been shown to result in relatively selective small fibre loss. ${ }^{18}$ The mechanism for pain in the presence of small fibre neuropathy has been considered in several reviews ${ }^{19-21}$ and the hypothesis that pain is a positive manifestation of nerve fibre disease affecting the nociceptive afferents seems eminently plausible. The precise pathophysiological basis of symptoms, however, is far from being understood.

In a study which examined nerve fibre pathology in teased sural nerve biopsy specimens from a group of patients with peripheral neuropathy, some of whom had moderate to severe neuropathic pain, an association between painfulness and the occurrence of acute breakdown of myelinated fibres was shown. The authors explain that since it was not possible to distinguish between myelin remnants from large and small myelinated fibres they were not able to provide direct evidence that painfulness was correlated with degeneration of a particular nerve fibre group..$^{22}$ Others have argued that there is evidence from morphological studies that the presence of dysesthetic pain correlates with sprouting of unmyelinated fibres. ${ }^{20}$ It has been suggested that in a distal axonopathy, axonal sprouts may become generators of spontaneous activity behaving in the same way as proximal fibre stumps in neuromas. ${ }^{23}$ Alternatively, pain could be arising from ephaptic transmission of either ascending or descending impulses crossing into pain fibres. ${ }^{19}$

Evidence is accumulating from microneurography studies that in some instances, positive neurogenic symptoms may be due to abnormal afferent fibre activity. ${ }^{12124}$ As yet, however, no microneurography recordings have been made showing spontaneous activity in C-fibres in patients with painful neuropathy.

Tenable hypotheses exist as to the cause of painful burning feet in patients with peripheral neuropathy. The almost indistinguishable symptoms in the group of patients with normal 
thermal thresholds are more difficult to explain. It seems probable that alterations in the central nervous system could produce peripheral sensations of pain and this may be the mechanism underlying the syndrome of "painful legs and moving toes" described by Spillane et $a l^{25}$ Schott reported five such cases who developed painful legs and moving toes following trauma to the feet and proposed that the trauma may have set up a spreading irritative central disorder possibly in the lower spinal cord. ${ }^{26}$ Ekbom's syndrome is another disorder in which there is a combination of pain in the legs relieved by movement. $^{27}$ Although some cases are associated with a neuropathy, ${ }^{28}$ this is not a prerequisite and two cases of restless legs have been described in association with arborising telangectasia. ${ }^{29}$

A yet further possibility exists which is that pain is arising from the nerve endings in nerve trunks-the nervi nervorum. Such a mechanism would be consistent with normal peripheral nerve function and therefore the findings of normal thermal thresholds. Other expected clinical features of such a disorder were not seen; there was no noticeable tenderness of the nerve bundles and symptoms were not exacerbated by movement or any other procedure that might have stretched the nerves.

Ochoa recently described a new syndrome, the "Painful ABC syndrome" (Angry Backfiring $\mathrm{C}$ nociceptor syndrome). ${ }^{30}$ This has been proposed as a specific disorder of the conductance channels of the receptor membrane of $C$ nociceptors. These receptors, usually responsive to both heat and painful mechanical stimuli, become disordered in such a way that they operate in a state near to threshold due to "up-regulated thermal activation" and any incremental change resulting from mechanical stimulation is sufficient to bring firing frequency to a level for conscious sensation. This has been called "cross modality threshold modulation" and the phenomenon of pain, induced either by increasing temperature or light mechanical stimulation, has been referred to as "polymodal hyperalgesia". The patients described as having this new syndrome presented with localised burning pain, hyperalgesia on thermal or mechanical stimuli, and gave histories illustrating the phenomena of cross modality threshold modulation. A notable finding was relief of symptoms by cooling the affected part. Although five patients in our series gave a history of relief from pain by placing their feet in cold water, only one had erythema and skin warming accompanying the pain. This exception (case 7) was shown on biopsy to have a vasculitic, small fibre neuropathy and in retrospect, probably had the "Painful ABC syndrome". We were unaware of the significance of the observation of the effect of cooling on symptoms at the time of the study, but these patients were all so troubled by their symptoms and eager to report any further self-observation that might have provided a clue as to the cause of their affliction, that it is unlikely we missed other cases of this syndrome. While carrying out the temperature threshold testing, a striking observation was the normal appearance of the patients' painful feet.

There remains the real possibility that the patients with pain and normal thermal thre- sholds have a neuropathic disorder which affects only those unmyelinated fibres involved with pain. ${ }^{17}$ In summary, the essential finding from this study is that a high proportion of patients with painful burning feet have normal thermal thresholds and possible pathophysiological mechanisms for their symptoms remain obscure.

The nerve biopsy were carried out by Dr Jean Jacobs. We wish to thank Dr R G Willison and Dr Jose Ochoa for helpful discussion and invaluable advice. We also thank the physicians at The National Hospital, Queen Square for permission to study their patients. ZA was supported by a grant given by Imperial Chemical Industries.

1 Ochoa J. Mechanisms of symptoms in neuropathy. In: Ellingson RJ, Murray NMF, Halliday AM, eds. The Ellingson RJ, Murray NMF, Halliday AM
London Symposium. EEG 1987;39:121-7.

2 Buchthal F, Rosenfalck A, Behse F. Sensory potentials in normal and diseased nerves. In: Dyck PJ, Thomas PK, Lambert EH, Bunge R, eds. Peripheral neuropathy. Philadelphia: Saunders, 1984:981-1015.

3 Hallin RG, Torebjork HE, Wiesenfeld $Z$. Nociceptors and warm receptors innervated by $\mathrm{C}$ fibres in human skin. J Neurol Neurosurg Psychiatry 1982;45:313-19.

4 Ochoa J. Recognition of unmyelinated fiber disease: morphologic criteria. Muscle Nerve 1978;1:375-87.

5 Heimans JJ, Bertelsmann FW, Van Rooy JCGM. Large and small nerve fibre function in painful diabetic neuropathy. J Neurol Sci 1986;74:1-9.

6 Jamal GA, Hansen S, Weir AI, Ballantyne JP. The neurophysiological investigation of small fiber neuropathies. Muscle Nerve 1987;10:537-45.

7 Report and Recommendations of the San Antonio Conference on Diabetic Neuropathy. Diabetes Care 1988; 11:592-7.

8 Jarvilehto $T$, Hamalaien $H$. Touch and thermal sensations: Psychophysical observations and unit activity in human skin nerves. In: Kenshalo DR, ed. Sensory functions of the skin of humans. New York: Plenum Press, 1980:279-95.

9 Konietzny $F$, Hensel $H$. The dynamic response of warm units in human skin nerves. Pflugers Arch 1977;370:111-4.

10 Fowler CJ, Sitzoglou K, Ali Z, Halonen P. The conduction velocities of peripheral nerve fibres conveying sensations of warming and cooling. J Neurol Neurosurg Psychiatry 1988;51:1164-70.

11 Gilliatt RW, Sears TA. Sensory nerve action potentials in patients with peripheral nerve lesions. $J$ Neurol Neurosurg Psychiatry 1958;21:109-18.

12 Kimura J. In: Kimura J, ed. Electrodiagnosis in diseases of nerve and muscle. Philadelphia: Davis, 1983.

13 Fowler CJ, Carroll MB, Burns D, Howe N, Robinson K. A portable system for measuring cutaneous thresholds for warming and cooling. J Neurol Neurosurg Psychiatry 1987;50:1211-15.

14 Dyck PJ, Zimmerman IR, O'Brien PD, Ness A, Caskey PE, Karnes J, Bushek W. Introduction of automated systems to evaluate touch-pressure, vibration, and thermal cutaneous sensation in man. Ann Neurol 1978;4:502-10.

15 Le Quesne PM, Fowler CJ, Parkhouse N. Peripheral neuropathy profile in various groups of diabetics. J Neurol neuropathy profile in various groups of dia
Neurosurg Psychiatry 1990;53, 7:558-63.

16 Kenshalo DR, Decker T, Hamilton A. Spatial summation on the forehead, forearm, and back produced by radiant and conducted heat. J Comp Physiol Psychol 1967;3:510-15.

17 Cline MA, Ochoa J, Torebjork HE. Chronic hyperalgesia and skin warming caused by sensitized $C$ nociceptors. Brain 1989;112:621-47.

18 Thomas PK. The anatomical substratum of pain. Can J Neurol Sci 1974;1:92-7.

19 Thomas PK. Pain in peripheral neuropathy: clinical and morphological aspects. In: Culp WJ, Ochoa J, eds. Abnormal nerves and muscles as impulse generators. New York: Oxford University Press, 1982:553-67.

20 Asbury AK, Fields HL. Pain due to peripheral nerve damage: an hypothesis. Neurology 1984;34:1587-90.

21 Ochoa J. Pain in local nerve lesions. In: Culp WJ, Ochoa J eds. Abnormal nerves and muscles as impulse generators. New York: Oxford University Press, 1982:568-87.

22 Dyck PJ, Lambert EH, O'Brien PC. Pain in peripheral neuropathy related to rate and kind of fiber degeneration. neuropathy related to rate and

23 Wall PD, Gutnick M. Properties of afferent nerve impulses originating from a neuroma. Nature 1974;248:740-3.

24 Nordin M, Nystrom B, Wallin U, Hagbarth KE. Ectopic sensory discharges and paraesthesiae in patients with disorders of peripheral nerves, dorsal roots and dorsal columns. Pain 1984;20:231-45.

25 Spillane JD, Nathan PW, Kelly RE, Marsden CD. Painfu legs and moving toes. Brain 1971;94:541-56.

26 Schott GD. "Painful legs and moving toes": the role of trauma. J Neurol Neurosurg Psychiatry 1981;44:344-6.

27 Ekbom KA. Restless legs syndrome. Neurology 1960;10: 868-73.

28 Read DJ, Feest TG, Nassim MA. Clonazepam: effective treatment for restless legs syndrome in uraemia. $B M J$ 1981;283:885-6.

29 Metcalfe RA, Macdermott N, Chalmers RJG. Restless red legs: an association of the restless legs syndrome with legs: an association of the restless legs syndrome with Neurosurg Psychiatry 1986;49:820-23.

30 Ochoa J. The newly recognized painful ABC syndrome: Thermographic aspects. Thermology 1986;2:65-107. 